How does plateau crust, thickening as the rift margins are approached, join with the attenuated crust of the rift floors? Does the rift Moho, evolve in nature and depth in the way proposed by Mueller ${ }^{18}$ ? Finally, is it possible that the detailed gravity signature for Africa expresses sublithospheric mantle convection (as postulated on other grounds by Thiessen et al. ${ }^{19}$ with horizontal dimensions of about $1,000 \mathrm{~km}$ ? A rather similar figure has recently been derived from bathymetry-geoid measurements for the Pacific by McKenzie et al. ${ }^{20}$, hinting that mantle convection beneath oceans and continents is of similar if not identical form.

\title{
Is fibroblast interferon antigenic for man?
}

\section{from D. A. J. Tyrell}

IN this issue of Nature (p.496) Vallbracht et al. report the treatment of a child with interferon $\beta$ for the malignant disease, neuroblastoma. Interferons are known to act against experimental tumours, possibly by inhibiting cell division and enhancing immune activity, for example by activating natural killer cells. As fibroblast interferon is not usually found in the circulation after intramuscular or subcutaneous injection, possibly because it is bound by tissues, it is given intravenously when a systemic effect is required in clinical studies. In the case reported by Vallbracht et al. there was a poor clinical response and while monitoring the pharmacokinetics of the injected interferon it was found that there was no interferon in the blood. An antiinterferon globulin was detected in the circulation, apparently in consequence of

D. A. J. Tyrell is in the Medical Research Council Clinical Research Centre, Harrow, UK. the repeated interferon injections. This did not appear in other patients. What does this mean?

From analysis of cloned human genes it is clear that interferons are families of molecules. Apparently there are distinct genes for eight different forms of interferon $\alpha$ (IFN- $\alpha$ or leukocyte interferon), and IFN- $\beta$ (fibroblast interferon) may also be the product of more than one gene. All interferons do, however, seem to be 'poor' antigens - in the practical sense that it is difficult to make antisera against them.

Nevertheless, antibodies against interferons have been produced by inoculating them into foreign species, and in a recent example a mouse immunized against human IFN- $\alpha$ - exactly which one we do not know - provided a monoclonal antibody-producing hybridoma. Immunoglobulin from the hybridoma has been used to purify interferon for clinical study (Secher and Burke Nature 285, 446; 1980), and may also be used for radioimmunoassay.

One would not expect to be able to produce antibodies by inoculating an interferon into the same species as the one which produced it. In general, immune responses are not mounted against normal constitutuents of cells because of a 'self/non-self' recognition mechanism which distinguishes between normal tissue components and novel and presumably extraneous antigens. However, as a transient response to tissue damage and as part of the 'autoimmune' diseases antibodies can be produced against normal tissue constitutents. This reaction seems particularly likely when the tissue component, for instance thyroglobulin, does not ordinarily enter the circulation and encounter cells of the immune system.

Did the patient treated by Vallbracht $e t$ $a l$. have some impairment of the self/nonself mechanism and thus react in this way? Is IFN $-\beta$ normally found only in or near to producing cells, so it is recognized as foreign when it enters the circulation? Was the IFN- $\beta$ given subtly different from the patient's own IFN- $\beta$, perhaps because it was the product of a different gene or because it was modified or denatured during manufacture? It remains to be seen whether anti-interferon antibodies are anything but an occasional nuisance when trying to treat patients with interferon no such trouble seems to have arisen during the treatment of substantial numbers of patients with IFN- $\alpha$. However, the single case report stimulates us to ask questions about the biology of interferon which we might otherwise not have thought of asking, and that must be a good thing.

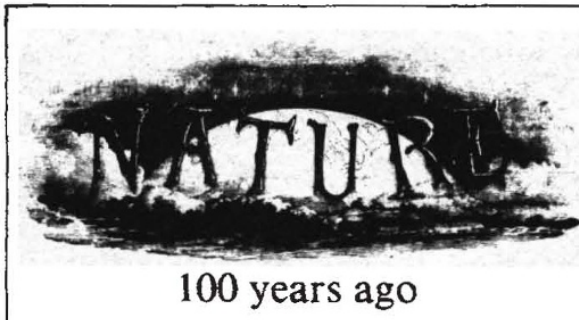

DR. LENZ, the German traveller who lately accomplished the feat of reaching Timbuctoo from the north, has arrived at Bordeaux, and is expected at Berlin soon to give an account of his explorations.

NEws from Cairo states that to the north of Memphis, near Saggarah, two pyramids have been discovered which were constructed by kings of the sixth dynasty, and the rooms and passages of which are covered with thousands of inscriptions. The discovery is said to be of the greatest scientific importance.

The habits of the Pleurodeles seem to be more or less like that of our native Tritons. During the procreative season they remain upright in the water; later they leave it and hide themselves in damp places under stones. Like the Water Newts, they posses a sort of cry; when frightened, as on being suddenly seized,

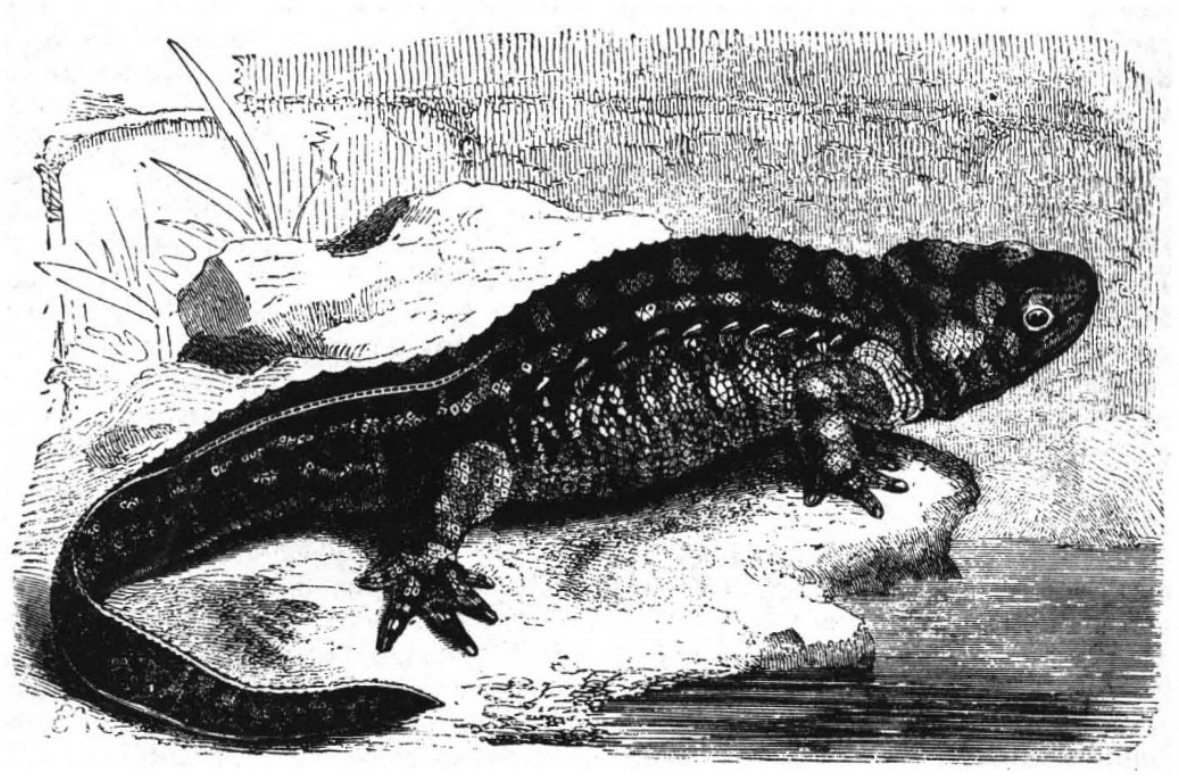

they emit a low, short, almost squeaking sound, generally repeated several times. This seemed to come not so much from the throat as to be caused by a rapid expulsion of air through the openings of the nose - in fact, to be a sort of snort.

It would almost seem worth one's while to
Pleurodeles waltlii

pay a visit to those Andalusian tanks, and by their semi-limpid sides and under the shelter of their surrounding fig and olive-trees work out the complete history of this interesting little form.

From Nature 23, 3 February, 1881. 